is certainly nothing new or fruitful either in psychological or metaphysical principle or treatment. As a foundation-laying even for the following works it seems to us to lack point.

The second volume, on the other hand, seems to us to be somewhat original in substance and manner of treatment, and is certainly fruitful in suggestion as well as principle. The work will repay reading, and we may look forward to the completion of the entire series with interest.

George S. Painter.

GHORGE WASHINGTON UNIVERSITY.

\title{
MENTAL EVOLUTION.
}

Natural Selection and Self-conscious Development. H. W. Wright. Philos. Rev, 1905, XIV., 40-56.

In order to determine whether natural selection is a governing law in self-conscious development, it is necessary (I) to examine the nature of natural selection as it was originally described and held to be operative in connection with the evolution of the organism, and (2) to note the distinguishing characteristics of the sphere of intelligence and obligation, to which it is proposed by some to apply the law of natural selection.

The view of natural selection adopted by the author is the extreme mechanical interpretation of Darwin. From the Origin of Species he finds warrant for saying that natural selection depends upon interaction (I) between organism and environment, and (2) between individual organisms. In both cases the interactions are between agencies which are externally related. In contrast with this external form of relation existing between the agencies in natural selection, it is pointed out that the relation of the conscious self to the objective world is not external and physical but functional and organic. This unique relation is so intimate that the self owes its development and existence as a person to its relations with the objective world, and the world owes its character and meaning to its relation to the self-conscious individual. The relation of individuals to each other is also not external, but intimate. The meaning and opportunities of the environment increase as the number of individuals increases.

Such a wide difference in conditions results in the world of selfconscious developnent, in a kind of adjustment different from that which arises under natural selection. The environment must supply ends which appeal to the individual as worthy of pursuit. Since the 
character of the environment depends on the individual, there need be no scarcity of ends, and since the relation of the individuals to each other is so vital there is no occasion for conflicting interests. Consequently there is no 'struggle for existence' and therefore no natural selection as found in the organic world. However, the author disclaims any intention of implying a break in the continuity of the evolutionary process. He recognizes both the physical and teleological factors, but emphasizes the teleological factor in the higher grades of development.

Realizing certain difficulties of this position, the anthor raises and replies to a number of objections. Is not the adjustment of the individual to the environment imperfect because many of the ends sought are unattainable? In answer it is to be said that the environment is only responsible for the totality of ends. The choice of specific ends rests with the individual. But are not certain ends forced upon the individual, - life, for instance? Mere existence, by the majority, is given a subordinate place among the ends that govern them. Is not organic existence indispensable to the attainment of the ends of intelligence? The environment is sufficiently well adjusted to render existence possible, and furthermore the individual can transform his environment. In the extreme case where existence is cut off, we may saly that the true significance of self-conscious life is not to be estimated by the length of physical existence. As to the relation of individuals to each other, the difficulties which arise on account of the fierce competition which actually exists in intelligent society are not discussed, but are declared to be not insoluble.

ESTHER HEMPHILL.

YALE UNIVERSITY.

\section{Essai sur l'évolution psychologique du jugement. THÉoDone}

Ruyssen. Paris, Alcan, 1904. Pp. $3^{32 .}$

This title is misleading, for the book is by no means exclusively devoted to the study of judgment, but discusses all forms of consciousness, in the order of simple and early to complex and late, without in the least making good their claim to be considered forms of judgment. The thesis of the book is well formulated on page 242 , where the author says: "In the preceding pages we have considered knowledge (la connaissance) as a process, no longer logical but dynamical, * * as an adaptation of all the physico-mental organism to an external stimulus." Adaptation, the author teaches, implies both the initiation of novel reactions and the repetition of actions already performed. He defines judgment, for example (p. $4^{8}$ ), as ' reaction, defensive or 